\title{
1.11. DERECHO Y POLÍTICAS AMBIENTALES EN LAS ISLAS BALEARES
}

(pp. 2-12)

\subsection{DRET I POLÍTIQUES AMBIENTALS A LES ILLES BALEARS (pp. 13-22)}

\author{
JoSÉ MANUEL GÓMEZ GONZÁLEZ \\ Departament de Territori. Consell Insular de Mallorca \\ Consultor \\ Universitat Oberta de Catalunya
}


Sumario: 1. Escasas novedades y alguna muy llamativa. 1.1. Producción normativa y efectos sobre un gobierno en minoría parlamentaria. 1.2. Acciones en política ambiental. A. La acción del Gobierno de las Islas Baleares en materia ambiental. B. Las políticas ambientales de los Consejos Insulares: el archivo de la modificación del Plan Territorial Insular de Ibiza. 2. Actividad legislativa. 2.1. Una polémica ley

I singular. 2.2. Una ley multipropósito. 3. Algunas iniciativas a destacar: la ampliación de la Red Ecológica Europea Natura 2000. 4. Breves noticias de actualidad ambiental. 5. Más sobre la declaración de la sierra de Tramuntana (Mallorca) como Patrimonio Mundial (UNESCO). 6. Notas sobre la incentivación de la custodia del territorio en Mallorca y Menorca. 6.1. Mallorca. 6.2. Menorca.

\section{Escasas novedades y alguna muy llamativa}

\subsection{Producción normativa y efectos sobre un gobierno en minoría parlamentaria}

En este número repasaremos las novedades en la normativa medioambiental de las Islas Baleares, que continua acorralada por las circunstancias políticas que describimos en el número de junio de la $R C D A$. Las novedades no son muy significativas, aunque las más relevantes tienen connotaciones contrarias al sentido de preservación ambiental que debe imperar en el derecho del medio ambiente. El hecho de contar con un gobierno de la Comunidad Autónoma que perdió el soporte de la mayoría parlamentaria con la salida de las instituciones de Unió Mallorquina ha provocado que las leyes en trámite provengan de proposiciones de ley de la oposición o sean proyectos de ley que pierden su redactado original por la vía de las enmiendas o de textos alternativos. Es muy probable que ni siquiera se tramiten los presupuestos generales de la Comunidad si no se dispone de un acuerdo básico sobre estos, lo que no deja de ser una situación que podríamos calificar de compleja.

\subsection{Acciones en política ambiental}

\section{A. La acción del Gobierno de las Islas Baleares en materia ambiental}

Como veremos, el Gobierno ha asumido la gestión del Parque Nacional MarítimoTerrestre del Archipiélago de Cabrera y ha procedido a nombrar al presidente del Patronato del Parque (Resolución del consejero de Medio Ambiente y Movilidad de 3 de junio de 2010). Sin embargo, es pronto para constatar cambios apreciables - de mejoría o viceversa- en la gestión de este emblemático espacio natural, muy especialmente en lo relacionado con intervenciones de conservación en sentido estricto (hasta ahora habían tenido mucho peso la construcción de infraestructuras y otras 
inversiones, muy por encima de las labores científicas y técnicas de conservación tanto marina como terrestre).

Otro frente abierto por el Gobierno ha sido el de ampliar determinados lugares de importancia comunitaria (LIC) y zonas de especial protección para las aves (ZEPA) de la Red Ecológica Europea Natura 2000 en Baleares, lo que puede valorarse muy positivamente.

Finalmente, en este semestre se ha revisado el régimen de parques zoológicos en las Islas Baleares y se ha procedido al traspaso a los consejos insulares (Mallorca, Menorca, Ibiza y Formentera) de los servicios y las competencias en materia de caza y de pesca fluvial.

B. Las políticas ambientales de los consejos insulares: el archivo de la modificación del Plan Territorial Insular de Ibiza

El Consejo Insular de Ibiza había iniciado la legislatura con el reto y la promesa de mejorar el marco normativo del Plan Territorial Insular (PTI) y corregir algunos vicios del texto del 2005 a favor de la sostenibilidad y de la mejora de aspectos ambientales. De esta forma, el Pleno del Consejo Insular de Ibiza de 30 de julio de 2010 acordó la aprobación inicial de la modificación del Plan Territorial Insular de Ibiza y sometió a información pública dicha aprobación inicial y su informe de sostenibilidad ambiental (ISA) de conformidad con lo previsto en la Ley 11/2006, de 14 de septiembre, de evaluaciones de impacto ambiental y evaluaciones ambientales estratégicas en las Illes Balears.

Sin embargo, el sábado 16 de octubre — según anunciaba el presidente del Consejo Insular-, ante el gran número de alegaciones presentadas y las dificultades de entendimiento y consenso político, una vez agotado el plazo de información pública y de consultas - tanto substantivas como ambientales - se tomó la decisión de retirar la propuesta de modificación y "empezar de nuevo". Al parecer se plantea trabajar en la creación de un consejo de territorio de carácter participativo, para diseñar la nueva propuesta. El Pleno del Consejo Insular de Ibiza ha de decidir sobre la retirada y 
devolución del documento aprobado en su fase inicial y ponerse a trabajar descartando todo lo realizado hasta ahora.

\section{Actividad legislativa}

\subsection{Una polémica ley singular}

Como habíamos avanzado en el número de junio de este año ${ }^{1}$, el Parlamento de las Islas Baleares estaba tramitando una curiosa proposición de ley singular de declaración de interés autonómico de un campo de golf. La proposición, que interpretaba como de interés general la inversión privada para la construcción de un campo de golf, planteaba algunas incógnitas que han persistido con la aprobación de la Ley 9/2010, de 27 de julio, de declaración de interés autonómico de la construcción del campo de golf de Son Bosc en Muro (BOIB núm. 115 de 05/08/2010). Ya hicimos hincapié, en el número de junio, en el hecho de que la norma que habilitaba para este tipo de declaraciones de interés autonómico era el Decreto Ley 1/2009, de 30 de enero, de medidas urgentes para el impulso de la inversión en las Illes Balears, que atribuye, en cuanto competencia ejecutiva, al Gobierno de las Islas Baleares — concretamente al Consejo de Gobierno ${ }^{2}$ la posibilidad de declarar determinados proyectos e inversiones privadas como de interés autonómico $-\mathrm{y}$ a los consejos insulares, la de declarar proyectos de interés insular ${ }^{3}$ - La aprobación de la Ley 9/2010, de 27 de julio, no aclara nada y siembra confusión. Nos encontramos ante una competencia ejecutiva del Gobierno que pasa a ser ejercida por el Parlamento sin que exista ningún precedente de leyes que realicen

\footnotetext{
1 Conviene la lectura del apartado de la crónica de Baleares del número de junio de 2010, para poder entender en toda su extensión el problema que genera la recién aprobada Ley 9/2010.

${ }^{2}$ Las inversiones de interés autonómico según el artículo 4 del DL 1/2009: "Son [...] las declaradas como tales por el Gobierno de las Islas Baleares por su especial relevancia para el desarrollo económico y social en su ámbito territorial". A continuación, el artículo 5 regula la declaración y tramitación de las inversiones de interés autonómico, y establece: "1. La declaración de una inversión de interés autonómico se adoptará por el Consejo de Gobierno a propuesta de cualquier Consejero en el ámbito de su respectiva competencia $[\ldots] "$.

3 Disposición adicional quinta. Inversiones de interés insular: "Los Consejos Insulares podrán acordar, mediante acuerdo del Consejo Ejecutivo adoptado a propuesta del titular del departamento respectivo, la declaración de inversión de interés insular que comportará, en cada ámbito territorial, los mismos efectos previstos para las inversiones de interés autonómico en el Capítulo II, del Título I, del presente Decreto Ley".
} 
este tipo de declaraciones singulares ejecutivas en substitución (o suplantación) del poder ejecutivo, lo que representa un ejemplo de deformación del sistema jurídico.

Probablemente el quid de la cuestión lo hallemos en la muy singular disposición derogatoria que, en su apartado 2, establece lo siguiente:

"En particular, queda derogado el acuerdo del Consejo de Gobierno de día 26 de febrero de 2010 sobre el inicio del procedimiento de elaboración del Plan de Ordenación de los Recursos Naturales de S'Albufera de Mallorca (isla de Mallorca), en todo lo que afecte a la finca registral número 16.091, del término municipal de Muro, sobre la que se ejecutan las instalaciones del campo de golf declarado de interés autonómico".

Por un lado, resulta chocante el hecho de que una ley "derogue" un acto administrativo de trámite (una orden de inicio de un PORN); por otro lado, resulta más chocante todavía la singularidad y dispensa sobre una finca registral en concreto (con el detalle del número), algo que supone todo un alarde de capacidad legislativa contrario al criterio defendido en diversos casos por el Consejo de Estado a propósito de leyes singulares.

De todas maneras, y para añadir más complejidad a todo este proceso, debemos recordar que en su día se aprobó el Decreto 52/2003, de 16 de mayo, de Modificación del Decreto 4/1988, de 28 de enero, de Declaración del Parque Natural de s'Albufera de Mallorca, que ampliaba el Parque Natural a la zona donde quiere construirse el campo de golf. De estar hoy en vigor este decreto del 2003, los terrenos donde se pretende construir el golf serían espacio natural protegido y, con la matriz de usos del suelo rústico de las Directrices de Ordenación Territorial y del Plan Territorial Insular de Mallorca, eso sería del todo imposible. Sin embargo, ese decreto del 2003 tiene sus "efectos paralizados" mediante el Acuerdo del Consejo de Gobierno de 30 de enero de 2004, que implicaba la retroacción del procedimiento de elaboración y de aprobación al 
momento de la exposición pública, por razones estrictamente formales ${ }^{4}$; sin embargo, parece justo afirmar que, al no haberse adoptado ningún acuerdo en contrario al de la retroacción ni ninguna orden de archivo del procedimiento, el trámite de ampliación del Parque Natural sigue en marcha - aunque sin avances aparentes - y permanece vigente la suspensión acordada en su día fundada en la referencia al artículo 7 de la Ley 4/1989 —entonces vigente- que establecía lo siguiente ${ }^{5}$ :

“1. Durante la tramitación de un Plan de ordenación de los recursos naturales no podrán realizarse actos que supongan una transformación sensible de la realidad física y biológica que pueda llegar a hacer imposible o dificultar de forma importante la consecución de los objetivos de dicho Plan.

2. Iniciado el procedimiento de aprobación de un Plan de ordenación de los recursos naturales y hasta que ésta se produzca no podrá otorgarse ninguna autorización, licencia o concesión que habilite para la realización de actos de transformación de la realidad física y biológica, sin informe favorable de la Administración actuante. Este informe sólo podrá ser negativo cuando en el acto pretendido concurra alguna de las circunstancias a que se refiere el número anterior".

Al no haber hecho la Ley 9/2010 expresa referencia a este procedimiento en tramitación que data del año 2003, difícilmente la disposición derogatoria genérica puede afectar a los efectos suspensivos de un procedimiento administrativo en trámite - que no deriva de una disposición normativa-y que está sujeto a los efectos de la legislación básica en materia de espacios naturales (hoy Patrimonio Natural y Biodiversidad), por lo que podemos afirmar que la Ley 9/2010, de 27 de julio, es completamente estéril en cuanto

\footnotetext{
${ }^{4}$ El acuerdo establecía concretamente:
}

"Primero.- Aceptar el requerimiento formulado por Don Miguel Ramis Martorell, Alcalde-Presidente del Ayuntamiento de Muro, en nombre y representación del mismo, contra el Decreto 52/2003, de 16 de mayo, de modificación del Decreto 4/1988, de 28 de enero, de declaración del parque natural de la Albufera de Mallorca, en cuanto modifica la delimitación del parque natural, anulando el acto impugnado y retrotrayendo el procedimiento al momento anterior al trámite de audiencia de los interesados.

Segundo.- Notificar el presente Acuerdo al Ayuntamiento de Muro, así como a cualquier otra persona que aparezca como interesada en el procedimiento, haciéndoles saber que, contra el mismo, que pone fin a la vía administrativa, podrán interponer recurso contencioso-administrativo ante la Sala Contenciosa-Administrativa del Tribunal Superior de les Illes Balears, en el plazo de dos meses a contar desde la notificación.

Tercero.- Publicar, a efectos de su conocimiento, el presente Acuerdo en el Boletín Oficial de las Illes Balears".

\footnotetext{
${ }^{5}$ Hoy esta previsión se correspondería con la del artículo 22 de la Ley 42/2007, de 13 de diciembre.
} 
a sus objetivos finales: permitir la construcción de un campo de golf en unos terrenos de elevado valor ambiental atendiendo a simples intereses particulares.

Por otra parte, el procedimiento de ampliación de la ZEPA que afecta a los terrenos donde quiere implantarse el campo de golf también impide cualquier transformación y la construcción del campo de golf; en este caso sería la Unión Europea la que podría actuar en defensa de la integridad de un procedimiento de modificación y ampliación de la Red Ecológica Europea Natura 2000 en ese lugar adyacente a un LIC y a una ZEPA de enorme valor.

\subsection{Una ley multipropósito}

La segunda ley con incidencia ambiental a comentar es la Ley 10/2010, de 27 de julio, de medidas urgentes relativas a determinadas infraestructuras y equipamientos de interés general en materia de ordenación territorial, urbanismo y de impulso a la inversión (BOIB núm. 115 de 05/08/2010). Este nuevo texto legislativo se inspira en las conocidas como leyes de acompañamiento a los presupuestos generales (o leyes de medidas administrativas, fiscales y del orden social...), con quince artículos que abordan temas tan dispares como calificar directamente unos sistemas de equipamientos (urbanismo legislativo), declarar de utilidad pública un centro de interpretación en Menorca (Centro de Interpretación de la Reserva de la Biosfera), alterar el régimen de los supuestos en los que se exonera la obligatoriedad de conectar al servicio de alcantarillado a edificaciones aisladas y núcleos de población también aislados, regular la práctica de las empresas de alquiler de coches impidiéndoles usar las vías públicas como aparcamientos masivos, regular los accesos a determinados caminos públicos de montaña, modificar la Ley de Carreteras, asignar el uso de una parcela urbana para destinarla a juzgados (Manacor e Ibiza), ampliar un equipamiento deportivo, asignar régimen urbano a unos terrenos en la franja denominada área de protección territorial de costas (en Ibiza) sin modificar formalmente el Plan Territorial Insular, alterar el régimen urbanístico de suelos que por legislación general no podrían considerarse directamente como urbanos, modificar por completo la Ley 8/1988, de 1 de junio, de edificios e instalaciones fuera de ordenación, o modificar la regulación de los establecimientos turísticos en suelo rústico con nuevas excepciones a las reglas generales. 
En conjunto, la mencionada ley incide negativamente en la preservación ambiental de base territorial, además de ser un muy mal ejemplo de técnica legislativa que contribuye a alterar la estructura del sistema jurídico bajo el formato de ley multipropósito. Por una parte, modifica planes urbanísticos sin someterlos a control ambiental (evaluación ambiental estratégica, que en las Islas Baleares se rige por la Ley 11/2006); por otra, relaja requisitos de prevención de la contaminación como la conexión al alcantarillado de núcleos de población y edificaciones aislados, altera el régimen de zonas afectadas por áreas de protección territorial (Ibiza) y, finalmente, flexibiliza los requisitos que han de cumplir los establecimientos hoteleros en suelo rústico.

\section{Algunas iniciativas a destacar: la ampliación de la Red Ecológica Europea Natura 2000}

Como contrapunto a la cuestionable actividad parlamentaria que hemos descrito en el apartado anterior, debemos destacar algunas iniciativas del Gobierno autonómico dirigidas a mejorar el estatus de protección de hábitats y especies de la Red Ecológica Europea Natura 2000 (formada al amparo de las directivas 92/43/CEE y la más reciente 2009/147/CE, que sustituyó a la pionera Directiva 79/409/CEE —Aves_-).

Así, se ha procedido a tramitar la ampliación de diversos LIC y ZEPA mediante sucesivos acuerdos del Consejo de Gobierno. Los tres acuerdos a destacar son: el de día 7 de mayo de 2010, sobre la iniciación del procedimiento de aprobación de la ampliación de la lista de lugares de importancia comunitaria (LIC) en cuanto al hábitat balsas temporales mediterráneas, y de ampliación y de actualización de la información del LIC ES5310037 Balsas de Llucmajor; el de día 9 de julio de 2010, sobre la ampliación de la zona de especial protección para las aves (ZEPA) de s'Albufera de Mallorca (ES 0000038); y el de día 24 de septiembre de 2010, sobre la aprobación de la ampliación de la lista de lugares de importancia comunitaria (LIC) en cuanto al hábitat de las lagartijas de las Islas Baleares.

Con respecto a la ampliación de la ZEPA de s'Albufera de Mallorca, el acuerdo colisiona de nuevo con el controvertido campo de golf de Son Bosc en el término municipal de Muro (Mallorca), que ha recibido la calificación de infraestructura de 
interés autonómico con la Ley 9/2010 comentada en el apartado II.1 de esta crónica, lo que implica que la Ley pueda ser cuestionada por la UE.

Más pacífica resulta la revisión de la situación de conservación de las lagartijas de las Islas Baleares al haberse detectado que 16 de los islotes que cuentan con la presencia de alguna de las dos especies protegidas no estaban incluidos en la Red Natura 2000. Las dos especies de lagartijas protegidas en nuestra Comunidad Autónoma son la variedad balear y la pitiusa. Están divididas en 87 poblaciones en islas e islotes. Se trata de un patrimonio genético de un interés extraordinario, tanto desde una perspectiva ecológica como evolutiva. Con la inclusión de estos islotes (especialmente de Menorca e Ibiza) se dota de una cobertura territorial casi completa a la preservación de los hábitats de las especies mencionadas.

\section{Breves noticias de actualidad ambiental}

A lo largo del semestre que analizamos en este número se han producido algunas novedades destacables en la organización administrativa del medio ambiente en Baleares. Por un lado, el Decreto 106/2010, de 24 de septiembre (BOIB número 142 de 30 de septiembre), aprueba el traspaso a los consejos insulares de las funciones y los servicios inherentes a las competencias propias de estas instituciones insulares que actualmente ejerce la Administración de la Comunidad Autónoma de las Islas Baleares en materia de caza y de regulación, vigilancia y aprovechamiento de los recursos cinegéticos, así como de pesca fluvial, lo que comporta un importante paso a la descentralización competencial a favor de la Administración insular. Por otra parte, se ha aprobado el Decreto 104/2010, de 10 de septiembre, por el que se regula la autorización y el régimen de funcionamiento de los organismos de control para la atmósfera y creación de su registro (BOIB número 138 de 21 de septiembre de 2010). También se ha completado el traspaso a la Comunidad Autónoma del Parque Nacional Marítimo-Terrestre del Archipiélago de Cabrera. Finalmente, se ha ordenado el régimen regulador de la autorización y el registro de los parques zoológicos en las Islas Baleares mediante el Decreto 69/2010, de 4 de junio (BOIB número 89 de 12 de junio de 2010). 


\section{Más sobre la declaración de la sierra de Tramuntana (Mallorca) como Patrimonio Mundial (UNESCO)}

Como ya apuntamos en el número de junio del 2010, el Consejo Insular de Mallorca está impulsando la candidatura de la sierra de Tramuntana ${ }^{6}$ para que sea declarada Patrimonio Mundial de la UNESCO como paisaje cultural. El trámite se encuentra en un estado avanzado y ha completado una de las últimas inspecciones y revisiones de la UNESCO antes de decidir sobre la declaración. A principios del mes de noviembre se ha procedido a enmendar y ampliar la información proporcionada a la UNESCO, después de la inspección realizada por $\operatorname{ICOMOS}^{7}$, organismo responsable de los lugares y monumentos históricos en el mundo y que se encarga de supervisar en nombre de la UNESCO los valores de las candidaturas presentadas a Patrimonio Mundial.

Como ya comentamos en su día, esta iniciativa fue lanzada por el Departamento de Territorio del Consejo Insular de Mallorca a principios de la legislatura actual, y ha cristalizado lentamente hasta superar los difíciles filtros que se interponen en el camino hacia la declaración como Patrimonio Mundial de la UNESCO al amparo de la Convención de París de $1972^{8}$. En este momento se ha creado el ente gestor del Patrimonio Mundial, un consorcio interadministrativo formado inicialmente por el Consejo Insular de Mallorca (como líder de la actuación) y el Gobierno de las Islas Baleares. El consorcio se ha aprobado definitivamente y en breve iniciará su actividad poniendo en práctica nuevos procesos participativos e implementando el conjunto de acciones que componen el plan de gestión; el plan incluye acciones en materia de comunicación, de desarrollo económico, de divulgación, de patrimonio y de gestión de visitantes.

\footnotetext{
${ }^{6}$ La sierra de Tramuntana es un ejemplo de creación de un paisaje singular gracias al trabajo durante siglos de distintas generaciones y culturas, y está considerada como uno de los enclaves naturales de más valor de las Baleares, con una superficie en torno a las 80.000 hectáreas. Los valores excepcionales que representa, tanto desde un punto de vista estético, etnológico y cultural, como físico, biológico y científico, hacen de este lugar un espacio único y avalan la candidatura de la sierra para formar parte de la lista de Patrimonio Mundial de la UNESCO. Véase: $\underline{\text { http://www.serradetramuntana.net/ca/ }}$

${ }^{7}$ http://www.icomos.org/

${ }^{8}$ Convención para la Protección del Patrimonio Mundial, Cultural y Natural de París (23 de noviembre de 1972): instrumento de aceptación de España de 18 de marzo de 1982. En la actualidad España cuenta con 41 espacios declarados Patrimonio Mundial.
} 


\section{Notas sobre la incentivación de la custodia del territorio en Mallorca y Menorca}

\subsection{Mallorca}

Entre el 28 y el 30 de octubre han tenido lugar las "I Jornadas de Custodia del Territorio en Mallorca. Diálogos para la Conservación del Patrimonio Natural y Cultural”. Estas jornadas las ha organizado la plataforma de segundo nivel Impulsores de la Custodia del Territorio en las islas Baleares (ICTIB ${ }^{9}$ ), cuya finalidad es cohesionar las actividades de custodia en las Islas.

Las Jjornadas han cubierto el objetivo de abrir un espacio de debate y de reflexión con diferentes agentes de la sociedad mallorquina y balear para impulsar la custodia del territorio en Mallorca como herramienta de diálogo para la conservación y el buen uso de los recursos naturales, culturales y paisajísticos. El éxito de participación avala la buena salud del concepto - la custodia del territorio ${ }^{10}$ - , que surge a mitad del siglo XIX en los Estados Unidos de América y en Inglaterra y se consolida con la creación de las primeras entidades de custodia a partir de 1891: los Trustees of Reservations (EE. UU.) y el National Trust (Inglaterra).

La utilización de instrumentos privados de conservación de la naturaleza surge como refuerzo de la función pública ambiental y responde a los objetivos generales comunes de cuidar nuestro patrimonio. La custodia es una "contribución al interés general" que se configura a partir de determinados valores éticos generados en torno a las relaciones entre los seres humanos y la naturaleza, que pueden enriquecerse con el sentido que adopta el principio constitucional "de indispensable solidaridad colectiva" con relación al derecho a un medio ambiente adecuado. Estos valores éticos están muy presentes y son especialmente sólidos en los movimientos y las instituciones del land stewardship norteamericanos; por el contrario, en nuestro país el elemento ético se está configurando lentamente a partir de otros conceptos - como la responsabilidad social o la perspectiva de obtener compensaciones directas o indirectas-. Sea cual sea la motivación que configura esta acción privada a favor de la conservación, lo que es indiscutible es que

\footnotetext{
9 http://ictib.org/

10 El concepto de custodia del territorio viene explicado en el artículo que publiqué en su día en Ecosostenible, ISSN 1699-3942, n. ${ }^{\circ}$ 16, 2006, págs. 37-49, titulado: "La Custodia del Territorio como instrumento de implicación social en la conservación del patrimonio natural".
} 
contribuye a un interés común que confluye con los intereses generales que tienen que defender los poderes públicos. Como dato a destacar dejaremos constancia de la demanda realizada por la red de iniciativas de custodia del territorio a favor de que se apruebe un marco normativo adecuado que incentive e impulse estos instrumentos de protección privada, un fenómeno que puede constituir una importante figura de refuerzo del objetivo de conservación del patrimonio natural.

\subsection{Menorca}

Un ejemplo destacable de custodia del territorio no los ofrece el Consejo Insular de Menorca con el instrumento de pago por servicios ambientales (PSA ${ }^{11}$ ) denominado Contrato Agrario de la Reserva de la Biosfera $\left(\mathrm{CARB}^{12}\right)$. Mediante un convenio firmado entre el Gobierno de las Islas Baleares y el Consejo Insular de Menorca, este año 2010 se van a destinar más de 1,6 millones de euros a las ayudas derivadas de la subscripción al CARB.

El Contrato Agrario de la Reserva de la Biosfera de Menorca nació en el 2005 como instrumento de gestión agraria pionero en España, destinado a fomentar las buenas prácticas sostenibles en el campo menorquín. Se trata de subscribir una serie de compromisos voluntarios y entrar en el programa de ayudas, tanto económicas como de asesoramiento, apoyo técnico y seguimiento o monitoreo.

${ }^{11}$ Una aproximación al pago por servicios ambientales puede verse en el siguiente informe resumido: http://www15.gencat.cat/cads/AppPHP/images/stories/publicacions/paperssostenibilitat/2010/ pds_16_web.pdf

12 Véase en http://www.ruralnaturaleza.com/contrato-agrario-de-la-reserva-de-la-biosfera-de-menorca y en http://www.cime.es/novacime/cim_CARB_conveni_juliol2010.pdf 
Sumari: 1. Novetats escasses i alguna de molt cridanera. 1.1. Producció normativa i efectes sobre un govern en minoria parlamentària. 1.2. Accions en política ambiental. A. L'acció del Govern de les Illes Balears en matèria ambiental. B. Les polítiques ambientals dels consells insulars: l'arxiu de modificació del Pla Territorial Insular d'Eivissa. 2. Activitat legislativa. 2.1. Una llei singular polèmica. 2.2. Una llei multipropòsit. 3. Algunes iniciatives que cal destacar: l'ampliació de la Xarxa Ecològica Natura 2000. 4. Breus notícies d'actualitat ambiental. 5. Més sobre la declaració de la serra de Tramuntana (Mallorca) com a Patrimoni Mundial (UNESCO). 6. Notes sobre el foment de la Custòdia del Territori a Mallorca i Menorca. 6.1. Mallorca. 6.2. Menorca.

\section{Novetats escasses i alguna de molt cridanera}

\subsection{Producció normativa i efectes sobre un govern en minoria parlamentària}

En aquest número repassarem les novetats en la normativa mediambiental de les Illes Balears que continua acorralada per les circumstàncies polítiques que vam descriure en el número de juny de la RCDA. Les novetats no són gaire significatives, tot i que les més rellevants tenen connotacions contràries al sentit de preservació ambiental que ha d'imperar en el dret del medi ambient. El fet de tenir un govern de la comunitat autònoma que va perdre el suport de la majoria parlamentària amb la sortida de les institucions d'Unió Mallorquina ha provocat que les lleis en tràmit provinguin de proposicions de llei de l'oposició o siguin projectes de llei que perden el redactat original per la via de les esmenes o de textos alternatius. És molt probable que ni tan sols es tramitin els pressupostos generals de la Comunitat si no es disposa d'un acord bàsic sobre els acords, la qual cosa no deixa de ser una situació que podríem qualificar de complexa.

\subsection{Accions en politica ambiental}

\section{A. L'acció del Govern de les Illes Balears en matèria ambiental}

Com veurem, el Govern ha assumit la gestió del Parc Nacional Marítim Terrestre de l'Arxipèleg de Cabrera i ha nomenat el president del Patronat del parc (Resolució del conseller de Medi Ambient i Mobilitat de 3 de juny de 2010). No obstant això, és aviat per constatar canvis apreciables - de millora o viceversa - en la gestió d'aquest espai natural emblemàtic, molt especialment en els aspectes relacionats amb intervencions de conservació en sentit estricte (fins ara la construcció d'infraestructures i altres inversions havia tingut molt pes, molt per sobre de les tasques científiques i tècniques de conservació tant marina com terrestre). 
Un altre front obert pel Govern ha estat el d'ampliar determinats llocs d'importància comunitària (LIC) i zones d'especial protecció per a les aus (ZEPA) de la Xarxa Ecològica Europea Natura 2000 a les Balears, la qual cosa pot valorar-se molt positivament.

Finalment, en aquest semestre, s'ha revisat el règim de parcs zoològics a les Illes Balears i s'han traspassat els serveis i les competències en matèria de caça i de pesca fluvial als consells insulars (Mallorca, Menorca, Eivissa i Formentera).

B. Les polítiques ambientals dels consells insulars: l'arxiu de modificació del Pla Territorial Insular d'Eivissa

El Consell Insular d'Eivissa havia iniciat la legislatura amb el repte i la promesa de millorar el marc normatiu del Pla Territorial Insular (PTI) i corregir alguns vicis del text de 2005 a favor de la sostenibilitat i de la millora d'aspectes ambientals. D'aquesta manera, el Ple del Consell Insular d'Eivissa de 30 de juliol de 2010 va acordar l'aprovació inicial de la modificació del Pla Territorial Insular d'Eivissa i va sotmetre a informació pública aquesta aprovació inicial i l'Informe de sostenibilitat ambiental (ISA) de conformitat amb el que preveu la Llei 11/2006, de 14 de setembre, d'avaluacions d'impacte ambiental i avaluacions ambientals estratègiques de les Illes Balears.

No obstant això, el dissabte 16 d'octubre — segons anunciava el president del Consell Insular - davant el gran nombre d'al·legacions presentades i les dificultats d'entesa i de consens polític, un cop exhaurit el termini d'informació pública i de consultes - tant substantives com ambientals - es va prendre la decisió de retirar la proposta de modificació i “començar de nou”. Segons que sembla, es planteja treballar en la creació d'un consell de territori de caràcter participatiu per dissenyar la nova proposta. El Ple del Consell Insular d'Eivissa ha de decidir sobre la retirada i devolució del document aprovat en la fase inicial, ha de posar-se a treballar i descartar tot el que s'ha realitzat fins ara. 


\section{Activitat legislativa}

\subsection{Una llei singular polèmica}

Com havíem avançat en el número de juny d'aquest any ${ }^{13}$, el Parlament de les Illes Balears estava tramitant una curiosa proposició de llei singular de declaració d'interès autonòmic d'un camp de golf. La proposició, que interpretava que la inversió privada per construir un camp de golf era d'interès general, plantejava algunes incògnites que han persistit amb l'aprovació de la Llei 9/2010, de 27 de juliol, de declaració d'interès autonòmic de la construcció del camp de golf de Son Bosc a Muro (BOIB núm. 115, de 5 d'agost de 2010). Ja vam insistir, en el número de juny, en el fet que la norma que habilitava per a aquest tipus de declaracions d'interès autonòmic era el Decret llei 1/2009, de 30 de gener, de mesures urgents per a l'impuls de la inversió a les Illes Balears, que atribueix, en tant que competència executiva, al Govern de les Illes Balears — concretament al Consell de Govern ${ }^{14}$ - la possibilitat de declarar determinats projectes $\mathrm{i}$ inversions privades com d'interès autonòmic - $\mathrm{i}$ als consells insulars, la de declarar projectes d'interès insular ${ }^{15}$. L'aprovació de la Llei 9/2010, de 27 de juliol, no aclareix res i sembra confusió. Ens trobem davant la competència executiva del Govern que passa a exercir el Parlament sense que existeixi cap precedent de lleis que realitzin aquest tipus de declaracions singulars executives en substitució (o suplantació) del poder executiu, la qual cosa representa un exemple de deformació del sistema jurídic.

Probablement el quid de la qüestió el trobem en la disposició derogatòria singular que en l'apartat 2 estableix:

\footnotetext{
13 Convé llegir l'apartat de la crònica de les Balears del número de juny de 2010 per poder entendre en tota la seva extensió el problema que genera la Llei 9/2010, aprovada recentment.

14 Segons l'article 4 del DL 1/2009, "Són inversions d'interès autonòmic les declarades com a tals pel Govern de les Illes Balears per la seva especial rellevància per al desenvolupament econòmic $\mathrm{i}$ social en el seu àmbit territorial." A continuació, l'article 5, regula la declaració i la tramitació de les inversions d'interès autonòmic, i estableix: “1. La declaració d'una inversió d'interès autonòmic és adoptada pel Consell de Govern a proposta de qualsevol conseller en l'àmbit de la seva respectiva competència".

15 Disposició addicional cinquena. Inversions d'interès insular. "Els consells insulars podran acordar, mitjançant acord del Consell Executiu adoptat a proposta del titular del departament respectiu, la declaració d'inversió d'interès insular que comportarà, a cada àmbit territorial, els mateixos efectes prevists per a les inversions d'interès autonòmic en el capítol II, del títol I, d'aquest Decret llei”.
} 


\begin{abstract}
"En particular, queda derogat l'acord del Consell de Govern de dia 26 de febrer del 2010 sobre l'inici del procediment d'elaboració del Pla d'ordenació dels recursos naturals de S'Albufera de Mallorca (illa de Mallorca), en allò que afecti la finca registral núm. 16.091, del terme municipal de Muro, sobre la que s'executen les instal-lacions del camp de golf declarat d'interès autonòmic".
\end{abstract}

D'una banda, resulta xocant el fet que una llei "derogui" un acte administratiu de tràmit (l'ordre d'inici del PORN); d'altra banda, resulta més xocant encara la singularitat i dispensa sobre una finca registral en concret (amb el detall del número), cosa que suposa tota una ostentació de capacitat legislativa contrària al criteri defensat en diversos casos pel Consell d'Estat a propòsit de lleis singulars.

De totes maneres, i per afegir més complexitat a tot aquest procés, hem de recordar que al seu dia es va aprovar el Decret 52/2003, de 16 de maig, de modificació del Decret 4/1988, de 28 de gener, de declaració del parc natural de l'Albufera de Mallorca, que ampliava el parc natural a la zona on vol construir-se el camp de golf. Si aquest decret del 2003 estigués avui en vigor, els terrenys on es pretén construir el golf serien espai natural protegit; i, amb la matriu d'usos del sòl rústic de les Directrius d'Ordenació Territorial i del Pla Territorial Insular de Mallorca, això seria del tot impossible. No obstant això, aquest decret de 2003 té els "efectes paralitzats" mitjançant l'Acord del Consell de Govern de 30 de gener de 2004 que implicava la retroacció del procediment d'elaboració i d'aprovació al moment de l'exposició pública, per raons estrictament formals ${ }^{16}$; no obstant això, sembla just afirmar que, com que no s'ha adoptat cap acord en contra al de la retroacció ni cap ordre d'arxiu del procediment, el tràmit d'ampliació del parc natural continua en marxa — encara que sense avanços aparents - i roman

\footnotetext{
16 L'acord estableix concretament:
}

Primer. Acceptar el requeriment formulat pel senyor Miquel Ramis Martorell, batle president de l'Ajuntament de Muro, en nom i representació d'aquest, contra el Decret 52/2003, de 16 de maig, de modificació del Decret 4/1988, de 28 de gener, de declaració del parc natural de l'Albufera de Mallorca, quant a modificar la delimitació del parc natural, anul'lant l'acte impugnat i retrotraient el procediment al moment anterior al tràmit d'audiència a les persones interessades.

Segon. Notificar aquest Acord a l'Ajuntament de Muro, així com a qualsevol altre persona que aparegui com a interessada en el procediment, i comunicar-los que contra aquest Acord, que exhaureix la via administrativa, es pot interposar un recurs contenciós administratiu davant la Sala Contenciosa Administrativa del Tribunal Superior de Justícia de les Illes Balears en el termini de dos mesos comptadors des de l'endemà d'haver-ne rebut la notificació.

Tercer. Publicar aquest Acord en el Butlletí Oficial de les Illes Balears amb l'efecte de ferlo públic. 
vigent la suspensió acordada al seu dia fundada en la referència a l'article 7 de la Llei 4/1989 - llavors vigent — que establia els punts següents ${ }^{17}$ :

“1. Durante la tramitación de un Plan de ordenación de los recursos naturales no podrán realizarse actos que supongan una transformación sensible de la realidad fisica y biológica que pueda llegar a hacer imposible o dificultar de forma importante la consecución de los objetivos de dicho Plan.

2. Iniciado el procedimiento de aprobación de un Plan de ordenación de los recursos naturales y hasta que ésta se produzca no podrá otorgarse ninguna autorización, licencia o concesión que habilite para la realización de actos de transformación de la realidad fisica y biológica, sin informe favorable de la Administración actuante. Este informe sólo podrá ser negativo cuando en el acto pretendido concurra alguna de las circunstancias a que se refiere el número anterior".

Ja que la Llei 9/2010 no fa referència expressa a aquest procediment en tramitació que data de l'any 2003, difícilment la disposició derogatòria genèrica pot afectar els efectes suspensius d'un procediment administratiu en tràmit — que no deriva d'una disposició normativa- i que està subjecte als efectes de la legislació bàsica en matèria d'espais naturals (avui Patrimoni Natural i Biodiversitat), per la qual cosa podem afirmar que la Llei 9/2010, de 27 de juliol, és completament estèril quant als seus objectius finals: permetre construir un camp de golf en terrenys de gran valor ambiental atenent simples interessos particulars.

D'altra banda, el procediment d'ampliació de la ZEPA que afecta els terrenys on es vol implantar el camp de golf, també impedeix qualsevol transformació i la construcció del camp de golf; en aquest cas, seria la Unió Europea la que podria actuar en defensa de la integritat d'un procediment de modificació i ampliació de la Xarxa Ecològica Europea Natura 2000 en aquest lloc adjacent a un LIC i una ZEPA de gran valor.

\subsection{Una llei multipropòsit}

La segona llei amb incidència ambiental que cal comentar és la Llei 10/2010, de 27 de juliol, de mesures urgents relatives a determinades infraestructures i equipaments

\footnotetext{
${ }^{17}$ Avui aquesta previsió es correspondria amb la de l'article 22 de la Llei 42/2007, de 13 de desembre.
} 
d'interès general en matèria d'ordenació territorial, urbanisme i d'impuls a la inversió (BOIB núm. 115, de 5 d'agost de 2010). Aquest nou text legislatiu s'inspira en les conegudes lleis d'acompanyament als pressupostos generals (o lleis de mesures administratives, fiscals i de l'ordre social...) amb quinze articles que aborden temes tan dispars com qualificar directament sistemes d'equipaments (urbanisme legislatiu), declarar un centre d'interpretació a Menorca d'utilitat pública (Centre d'interpretació de la Reserva de la Biosfera), o alterar el règim dels supòsits en què s'exonera l'obligatorietat de connectar al servei de clavegueram a edificacions aïllades i nuclis de població també aïllats, o regular la pràctica de les empreses de lloguer de cotxes i impedir-los usar les vies públiques com a aparcaments massius, o regular els accessos en determinats camins públics de muntanya, o modificar la llei de carreteres, o assignar l'ús d'una parcel·la urbana per destinar-la a jutjats (Manacor i Eivissa), o ampliar un equipament esportiu, o assignar règim urbà a uns quants terrenys en la franja anomenada Àrea de Protecció Territorial de Costes (a Eivissa) sense modificar formalment el Pla Territorial Insular, o l'alteració del règim urbanístic de sòls que per legislació general no podrien considerar-se directament com a urbans, o modificar per complet la Llei 8/1988, d'1 de juny, d'edificis i instal·lacions fora d'ordenació, o modificar la regulació dels establiments turístics en sòl rústic amb noves excepcions a les regles generals.

En conjunt, la llei esmentada incideix negativament en la preservació ambiental de base territorial, a més de ser un exemple molt dolent de tècnica legislativa que contribueix a alterar l'estructura del sistema jurídic sota el format de llei multipropòsit. D'una banda, modifica plans urbanístics sense sotmetre'ls a control ambiental (avaluació ambiental estratègica, que a les Illes Balears es regeixen per la Llei 11/2006); d'altra banda, relaxa requisits de prevenció de la contaminació, com la connexió al clavegueram de nuclis de població i edificacions aïllades; altera el règim de zones afectades per les Àrees de protecció territorial (Eivissa), i, finalment, flexibilitza els requisits que han de complir els establiments hotelers en sòl rústic.

\section{Algunes iniciatives que cal destacar: l'ampliació de la Xarxa Ecològica Europea} Natura 2000 
Com a contrapunt a la qüestionable activitat parlamentària que hem descrit en l'apartat anterior, hem de destacar algunes iniciatives del Govern autonòmic dirigides a millorar l'estatus de protecció d'hàbitats i d'espècies de la Xarxa Ecològica Europea Natura 2000 (conformada a l'empara de la Directiva 92/43/CEE i la Directiva 2009/147/CE, més recent, que va substituir la pionera Directiva 79/409/CEE - Aus-).

Així, s'ha tramitat l'ampliació de diversos LIC i ZEPA mitjançant successius acords del Consell de Govern. Els tres acords que cal destacar són: el de dia 7 de maig de 2010, sobre la iniciació del procediment d'aprovació de l'ampliació de la llista de llocs d'importància comunitària (LIC) quant a l'hàbitat Basses Temporals Mediterrànies i d'ampliació i d'actualització de la informació del LIC ES5310037 Basses de Llucmajor; el del dia 9 de juliol de 2010, sobre l'ampliació de la de la zona d'especial protecció per a les aus (ZEPA) de S'Albufera de Mallorca (és 0000038), i el del dia 24 de setembre de 2010, sobre l'aprovació de l'ampliació de la llista de llocs d'importància comunitària (LIC) quant a l'hàbitat de les sargantanes de les Illes Balears.

Respecte a l'ampliació de la ZEPA de S'Albufera de Mallorca, l'acord col·lideix novament amb el controvertit camp de golf de Son Bosc al terme municipal de Muro (Mallorca), que ha rebut la qualificació d'infraestructura d'interès autonòmic amb la Llei 9/2010, que hem comentat en l'apartat II.1 d'aquesta crònica, la qual cosa implica que la UE pot questionar la llei.

La revisió de la situació de conservació de les sargantanes de les Illes Balears resulta més pacífica, ja que s'ha detectat que setze dels illots que presenten alguna de les dues espècies protegides s'havien inclòs en la Xarxa Natura 2000. Les dues espècies de sargantanes protegides a la nostra comunitat autònoma són la varietat balear i la pitiüsa. Estan dividides en 87 poblacions d'illes i illots. Es tracta d'un patrimoni genètic d'un interès extraordinari, tant des d'una perspectiva ecològica com evolutiva. Amb la inclusió d'aquests illots (especialment de Menorca i Eivissa) es dota la preservació dels hàbitats de les espècies esmentades d'una cobertura territorial gairebé completa.

\section{Breus notícies d'actualitat ambiental}


Al llarg del semestre que analitzem en aquest número, s'han produït algunes novetats destacables en l'organització administrativa del medi ambient a les Balears. D'una banda, el Decret 106/2010, de 24 de setembre (BOIB número 142, de 30 de setembre), aprova el traspàs als consells insulars de les funcions $\mathrm{i}$ els serveis inherents a les competències pròpies d'aquestes institucions insulars que actualment exerceix l'Administració de la Comunitat Autònoma de les Illes Balears en matèria de caça i de regulació, de vigilància i d'aprofitament dels recursos cinegètics, així com de pesca fluvial, la qual cosa comporta un pas important a la descentralització competencial a favor de l'administració insular. D'altra banda, s'ha aprovat el Decret 104/2010, de 10 de setembre, pel qual es regula l'autorització i el règim de funcionament dels organismes de control per a l'atmosfera i creació del seu registre (BOIB número 138, de 21 de setembre de 2010). També s'ha completat el traspàs a la comunitat autònoma del Parc Nacional Marítim Terrestre de l'Arxipèleg de Cabrera. Finalment s'ha ordenat el règim regulador de l'autorització i el registre dels parcs zoològics a les Illes Balears mitjançant el Decret 69/2010, de 4 de juny (BOIB número 89, de 12 de juny de 2010).

\section{Més sobre la declaració de la serra de Tramuntana (Mallorca) com a Patrimoni Mundial (UNESCO)}

Com ja vam apuntar en el número de juny de 2010, el Consell Insular de Mallorca impulsa la candidatura de la serra de Tramuntana ${ }^{18}$ perquè sigui declarada Patrimoni Mundial de la UNESCO com a paisatge cultural. El tràmit es troba en un estat avançat i ha completat una de les últimes inspeccions i revisions de la UNESCO abans de decidir la declaració. Al principi del mes de novembre s'ha esmenat i ampliat la informació proporcionada a la UNESCO, després de la inspecció realitzada per $\operatorname{ICOMOS}^{19}$, organisme responsable dels llocs i dels monuments històrics del món i que s'encarrega

\footnotetext{
${ }^{18}$ La serra de Tramuntana és un exemple de creació d'un paisatge singular gràcies a la feina de diferents generacions i cultures durant segles, i està considerat com un dels enclavaments naturals de més valor de les Balears amb una superfície entorn a les 80.000 hectàrees. Els valors excepcionals que representa, tant des d'un punt de vista estètic, etnològic i cultural, com físic, biològic i científic, fan d'aquest lloc un espai únic i avalen la candidatura de la serra per formar part de la llista de Patrimoni Mundial de la UNESCO. Vegeu: <http://www.serradetramuntana.net/ca/>.

$19<\mathrm{http}: / /$ www.iconos.org $>$.
} 
de supervisar en nom de la UNESCO els valors de les candidatures presentades a Patrimoni Mundial.

Com ja vam comentar al seu dia, el Departament de Territori del Consell Insular de Mallorca va llançar aquesta iniciativa al principi de la legislatura actual, la qual va cristal·litzar lentament fins a superar els filtres difícils que s'interposen en el camí d'una declaració com a Patrimoni Mundial de la UNESCO a l'empara de la Convenció de París de $1972^{20}$. En aquest moment s'ha creat l'ens gestor del Patrimoni Mundial, un consorci interadministratiu format inicialment pel Consell Insular de Mallorca (com a líder de l'actuació) i el Govern de les Illes Balears. El consorci s'ha aprovat definitivament i d'aquí a poc temps iniciarà l'activitat, posarà en pràctica nous processos participatius i implementarà el conjunt d'accions que componen el Pla de Gestió; el Pla inclou accions en matèria de comunicació, de desenvolupament econòmic, de divulgació, de patrimoni, i de gestió de visitants.

\section{Notes sobre el foment de la Custòdia del Territori a Mallorca i Menorca}

\subsection{Mallorca}

Entre el 28 i el 30 d'octubre, han tingut lloc les I Jornades de Custòdia del Territori a Mallorca, Diàlegs per a la Conservació del Patrimoni Natural i Cultural. Aquestes jornades les ha organitzat la plataforma de segon nivell que s'encarrega de l'Impuls a la Custòdia del Territori a les Illes Balears $\left(\mathrm{ICTIB}^{21}\right)$, i la finalitat de les quals és cohesionar les activitats de custòdia a les Illes.

Les jornades han complert l'objectiu d'obrir un espai de debat i de reflexió amb diferents agents de la societat mallorquina i balear per impulsar la custòdia del territori a Mallorca, com a eina de diàleg per a la conservació i el bon ús dels recursos naturals, culturals i paisatgístics. L’èxit de participació avala la bona salut del concepte —la

\footnotetext{
20 Convenció per a la protecció del patrimoni mundial, cultural i natural de París (23 de novembre de 1972): instrument d'acceptació d'Espanya de 18 de març de 1982. Actualment Espanya té 41 espais declarats com a Patrimoni Mundial.

$21<$ http:ictib.org/>.
} 
custòdia del territori ${ }^{22}$ 一, que sorgeix a mitjan segle XIX als Estats Units d'Amèrica i a Anglaterra, i es consolida amb la creació de les primeres entitats de custòdia a partir de 1891: els Trustees of Reservations (els EUA) i el National Trust (Anglaterra).

La utilització d'instruments privats de conservació de la natura sorgeix per reforçar la funció pública ambiental i respon als objectius generals comuns de tenir cura del nostre patrimoni. La custòdia és una "contribució a l'interès general" que es configura a partir de determinats valors ètics que es generen entorn a les relacions entre els éssers humans i la natura, que poden enriquir-se amb el sentit que adopta el principi constitucional d"'indispensable solidaritat col·lectiva" amb relació al dret a un medi ambient adequat. Aquests valors ètics estan molt presents i són especialment sòlids en els moviments i les institucions del land stewardship dels EUA; per contra, al nostre país l'element ètic es configura lentament a partir d'altres conceptes — com la responsabilitat social o la perspectiva d'obtenir compensacions directes o indirectes. Sigui quina sigui la motivació que configura aquesta acció privada a favor de la conservació, el que és indiscutible és que contribueix a l'interès comú que conflueix amb els interessos generals que han de defensar els poders públics. Com a dada que cal destacar, deixarem constància de la demanda realitzada per la xarxa d'iniciatives de custòdia del territori a favor que s'aprovi un marc normatiu adequat que incentivi i impulsi aquests instruments de protecció privada, fenomen que pot constituir una figura de reforç important de l'objectiu de conservació del patrimoni natural.

\subsection{Menorca}

Un exemple destacable de custòdia del territori no l'ofereix el Consell Insular de Menorca amb l'instrument de Pagament per Serveis Ambientals (PSA ${ }^{23}$ ), anomenat

\footnotetext{
22 El concepte de Custòdia del Territori l'explico en l'article que vaig publicar en el seu dia a Ecosostenible, ISSN 1699-3942, N. 16, 2006, p. 37-49, titulat: "La Custòdia del Territori com a instrument d'implicació social en la conservació del patrimoni natural“".

23 Vegeu l'aproximació al pagament per serveis ambientals en el següent informe resumit: <http:// www15.gencat.cat/cads/AppPHP/images/stories/publicacions/paperssostenibilitat/2010/pds_16_web.pdf $>$.
} 
Contracte Agrari de la Reserva de la Biosfera $\left(\mathrm{CARB}^{24}\right)$. Mitjançant el conveni signat entre el Govern de les Illes Balears i el Consell Insular de Menorca, aquest any s'han destinat més d'1,6 milions d'euros a ajudes derivades de la subscripció del CARB.

El Contracte Agrari de la Reserva de la Biosfera de Menorca va néixer el 2005 com a instrument de gestió agrària pioner a Espanya, destinat a fomentar bones pràctiques sostenibles al camp menorquí. Es tracta de subscriure una sèrie de compromisos voluntaris i entrar en el programa d'ajudes, tant econòmiques com d'assessorament, suport tècnic i seguiment o monitoratge.

24 Consulteu-lo a <http://www.ruralnaturaleza.com/contrato-agrario-de-la-reserva-de-la-biosfera-demenorca $\mathrm{i}$ en http://www.cime.es/novacime/cim_CARB_conveni_juliol2010.pdf $>$. 